\title{
Inulin-enriched dairy desserts: Physicochemical and sensory aspects
}

\author{
L. González-Tomás, S. Bayarri, ${ }^{1}$ and E. Costell \\ Physical and Sensory Properties Laboratory, Instituto de Agroquímica y Tecnología de Alimentos, Consejo Superior de Investigaciones \\ Cientificas, PO Box 73, 46100 Burjassot, Valencia, Spain
}

\section{ABSTRACT}

The aim of this work was to study how adding inulin of different average chain lengths (long-chain, native, and short-chain inulin) at a concentration of $7.5 \%$ (wt/ wt) would affect the physicochemical and sensory characteristics of starch-based dairy desserts formulated with either skim or whole milk. The results have shown that the effect of adding $7.5 \%$ inulin of different average chain length can give rise to products with different rheological behavior and different sensory characteristics. The skim milk sample with long-chain inulin and the whole milk sample without inulin showed similar flow behavior. Both samples were perceived to have the same creaminess and consistency intensity, but addition of long-chain inulin increased roughness intensity and, consequently, the sensory quality could be negatively affected. The information obtained may be of great interest in designing new products with nutritional and sensory characteristics that meet consumer demands.

Key words: inulin, dairy dessert, flow behavior, sensory analysis

\section{INTRODUCTION}

New functional products are developed by modifying traditional food formulas, eliminating or replacing certain ingredients (fat, sugar) or adding wholesome compounds (e.g., soluble fiber, n-3 fatty acids, vitamins, phytosterols), which is, at least theoretically, the simplest and most commonly used method (Fogliano and Vitaglione, 2005). Nevertheless, certain problems can arise from the effect of interactions between the functional ingredients and the components of the food matrix. In nutritional terms, such effects can lead to decreased bioavailability of the added active ingredient or vary the optimal conditions for its absorption (Clydesdale, 2004), whereas in terms of quality, the sensorial characteristics of the final product may be

Received March 25, 2009.

Accepted May 5, 2009.

${ }^{1}$ Corresponding author: sbayarri@iata.csic.es altered, modifying the consumer response (Verbeke, 2006).

Inulin is a natural component of several fruits and vegetables and its nutritional properties are well known. Inulin ingestion affords the benefits inherent not only to its condition as a dietetic fiber (e.g., reducing blood cholesterol and lipid levels, intestinal traffic control, increasing calcium adsorption), but also those derived from its prebiotic nature, related mainly to stimulation of bifida-bacterial growth and regulation of intestinal flora in the colon (Roberfroid and Slavin, 2000). Chemically, native inulin is a mixture of oligomer and polymer chains with a variable number of fructose molecules, joined by $\beta$ bonds $(2 \rightarrow 1)$, which also usually include a glucose molecule at the end of the chain. The degree of polymerization of the chains varies between 2 and 60 units with an average of approximately 12 in native inulin. Short-chain inulin or oligofructose can be obtained by partial enzymatic hydrolysis of the native inulin, obtaining a polymerization degree between 2 and 7. Applying physical methods, long-chain inulin with an average polymerization degree varying between 22 and 25 can be obtained (Franck, 2002).

The prebiotic effect of inulin depends on numerous factors and particularly on the composition of the intestinal flora in each individual. Because of this individual variability, a generally valid dose cannot be established (Roberfroid, 2005). However, a minimum consumption of $5 \mathrm{~g} / \mathrm{d}$ is considered enough to increase the proportion of bifidus in the intestinal microflora, although most studies made in vivo have supplemented the diet with larger amounts (Roberfroid and Slavin, 2000). In most cases, its addition to different foods has aimed to supplement them to increase fiber ingestion, in amounts from 3 to $6 \mathrm{~g}$ per portion, or to assure its bifidogenic nature, adding 3 to $8 \mathrm{~g}$ per portion (Coussement, 1999). Another important factor is the possible influence exerted by the degree of fructose-chain polymerization on physiological effects, especially regarding prebiotic function. Depending on chain length, inulin fermentation takes place in different regions of the colon, the duration of metabolic activity varies, and there are variations in the physiological effects (Roberfroid, 2005; Stewart et al., 2008) 
Inulin also has interesting technological properties, such as a low-calorie sweetener, fat substitute, or its texture modifying capacity (Tungland and Meyer, 2002). These properties are also linked to the polymerization degree of its chains. Certain authors have analyzed the effect of different inulin concentrations on the rheological and sensorial characteristics of several dairy products such as yogurts (Kip et al., 2006) or dairy desserts (Tárrega and Costell, 2006; Cardarelli et al., 2008). Most of these works used only one inulin type, generally the long-chain type. There is less information about the effect of inulin with different degrees of polymerization on the rheological and sensory properties of dairy products. Villegas and Costell (2007) observed that the effect of inulin average chain length and inulin concentration on flow in milk beverages depended on the type of milk (skim or whole) and on whether $\kappa$-carrageenan was added. They showed that the viscosity of skim milk with 4 to $10 \%$ short-chain inulin, 6 to $8 \%$ native inulin, or with 4 to $6 \%$ long-chain inulin could approximate that of whole-milk beverages. Moreover, to obtain milk beverages with reduced fat content having similar thickness and creaminess to those perceived in whole-milk beverages, it was necessary to add long-chain inulin at concentrations $>8 \%$ (Villegas et al., 2007). In a previous work, González-Tomás et al. (2008) observed that inulin type and concentration had little effect on the viscoelasticity of whole-milk starchbased dairy desserts but were key factors in skim milk samples. These authors also observed that 2 of the skim milk samples, one containing $4 \%$ starch and $7.5 \%$ shortchain inulin and another with $3.25 \%$ starch and $7.5 \%$ long-chain inulin, had very similar viscoelastic properties to the whole milk sample with the same starch concentration. The information obtained indicated that, in general, adding inulin at concentrations lower than $5 \%$ to liquid and semisolid dairy products did not modify their characteristics and that long-chain inulin used as fat replacer in such products requires the addition of inulin at over $7 \%$ of the concentration.

Taking the above into consideration, the aim of this work was to study how adding inulin of different average chain lengths at a concentration of $7.5 \%$ (wt/wt) would affect the physicochemical and sensory characteristics of starch-based dairy desserts formulated with either skim or whole milk.

\section{MATERIALS AND METHODS}

\section{Samples}

Eight samples, 4 with whole milk and 4 with skim milk, were prepared with fixed amounts of medium cross-linked modified tapioca starch $(3.25 \%$, corrected for moisture content; $\mathrm{C}^{*}$ Creamtex 75720, Cerestar Ibérica, Barcelona, Spain), commercial whole (25\% wt/ wt protein, $39 \%$ wt/wt carbohydrate, $26 \%$ wt/wt fat, and $1.2 \% \mathrm{wt} / \mathrm{wt}$ calcium $)$ and skim $(34 \% \mathrm{wt} / \mathrm{wt}$ protein, $52 \% \mathrm{wt} /$ wt carbohydrate, $1 \% \mathrm{wt} / \mathrm{wt}$ fat, and $1.2 \%$ wt/wt calcium) milk ( $80 \%$ wt/wt; Central Lechera Asturiana, Siero, Spain), commercial sucrose (6\% wt/wt), vanilla aroma (0.016\% wt/wt; 375 48A, Lucta SA, Barcelona, Spain) and yellow-orange colorant $(0.052 \% \mathrm{wt} /$ wt; Vegex NC 2c WS mct, Chr. Hansen SA, Barcelona, Spain). Starch moisture content was determined with a LJ16 moisture analyzer (Mettler Toledo GmbHB, Greifensee, Switzerland). Three types of inulin that differed in the average chain length were added to the samples at a $7.5 \%$ concentration: long-chain inulin ( $\geq 23$ monomers; Frutafit Tex!); native (9-12 monomers; Frutafit IQ); and a short-chain inulin (7-9 monomers; Frutafit Clr), all provided by Sensus (Brenntag Química, Barcelona, Spain). Two more samples without added inulin (one prepared with whole milk and another prepared with skim milk) were used as controls.

Whole and skim milks were prepared in advance by dissolving $13.5 \%$ (wt/wt) milk powder in mineral water (33.5 mg of calcium/L, $6.6 \mathrm{mg}$ of magnesium/L, 12.2 $\mathrm{mg}$ of sodium/L, $135 \mathrm{mg}$ of bicarbonate/L, $11.6 \mathrm{mg}$ of sulfate/L, and $6.9 \mathrm{mg}$ of chloride content/L) to obtain a final fat content of 3.5 and $0.14 \%$, respectively, and were stored for $24 \mathrm{~h}$ at $4 \pm 1^{\circ} \mathrm{C}$.

Samples were prepared in $800-\mathrm{g}$ batches as follows: starch, sugar, and inulin were mixed in a flask and rehydrated milk was added at room temperature. The flask was placed in a water bath at $100 \pm 1^{\circ} \mathrm{C}$ and stirred constantly at around $200 \mathrm{rpm}$ with a propeller stirrer (Heidolph RZR 1, Germany) for 30 min, ensuring a period of at least $15 \mathrm{~min}$ at $86 \pm 1^{\circ} \mathrm{C}$, to be finally cooled in an ice bath until reaching about $40^{\circ} \mathrm{C}$ when the aroma was added. Any evaporated water was replaced gravimetrically with deionized water. The sample was stirred, transferred to a closed flask, and stored ( $4 \pm$ $1^{\circ} \mathrm{C} ; 48 \mathrm{~h}$ ) before measurements.

\section{Rheological Measurements}

Rheological measurements were carried out in a controlled stress rheometer RS1 (Haake, Karlsruhe, Germany), using a parallel plates geometry (60 mm diameter; $1 \mathrm{~mm}$ gap). A sample temperature of $10 \pm 1^{\circ} \mathrm{C}$ was kept during measurements by means of a Phoenix P1 Circulator device (Thermo Haake). Two batches of each composition were prepared and at least one measurement was performed on each batch, using a fresh sample for each measurement. After loading the sample, a waiting period of $10 \mathrm{~min}$ was used to allow the sample to stabilize and reach the desired temperature. 
Table 1. End terms and definitions of the odor, appearance, flavor, and texture descriptors used in the sensory evaluation of the dairy desserts

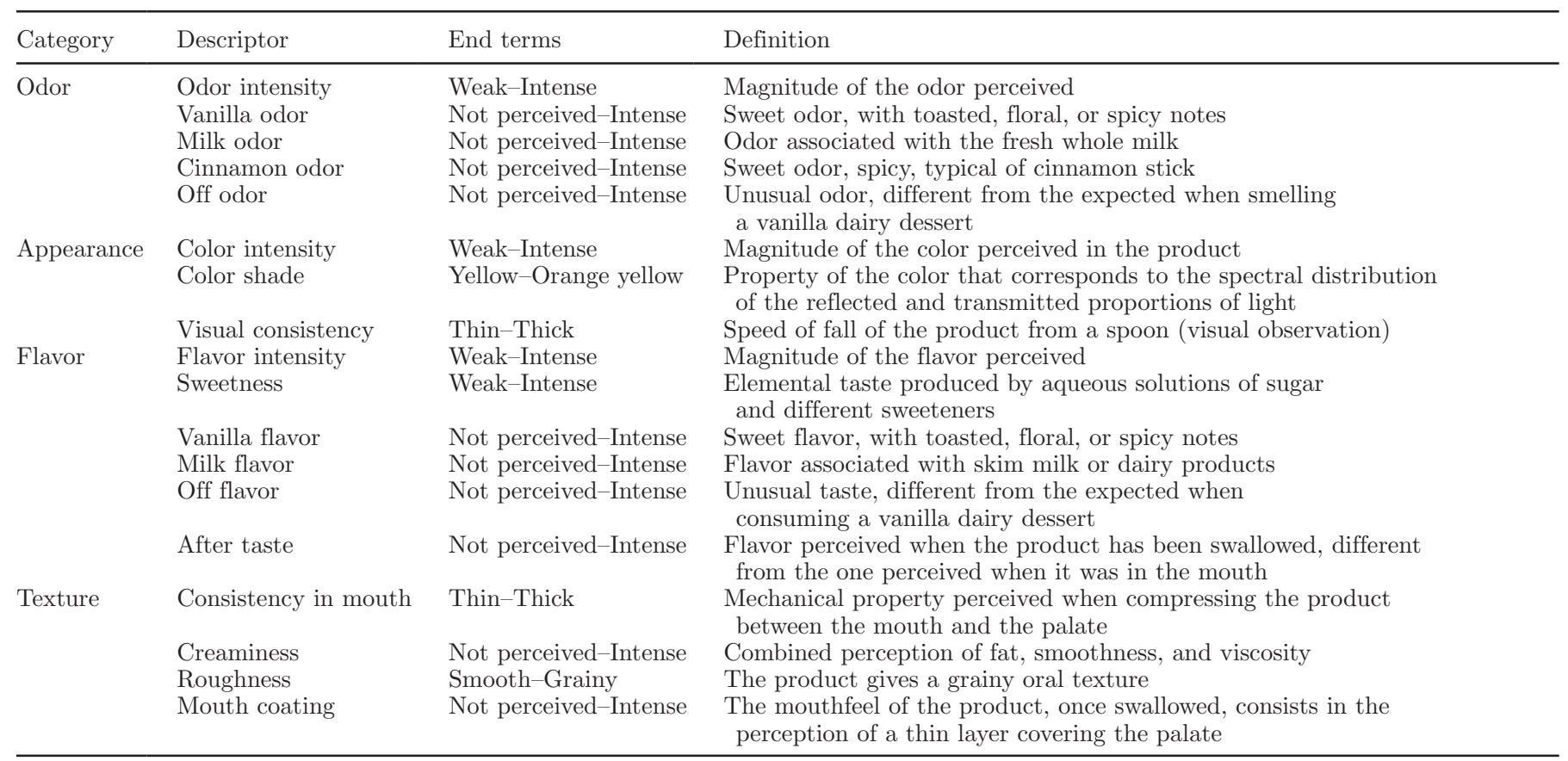

Samples flow was measured by recording shear stress $(\sigma)$ values when shearing the samples with an increasing shear rate $(\dot{\gamma})$ from 1 to $200 \mathrm{~s}^{-1}$ for a period of $60 \mathrm{~s}$ and in reverse sequence for the same time (GonzálezTomás and Costell, 2006a). Data from the ascending segment of the shear cycle were fitted to the Ostwald de Waele model [1] using Rheowin Pro software (v. 2.93, Haake), where $\mathrm{K}\left(\mathrm{Pa} \cdot \mathrm{s}^{\mathrm{n}}\right)$ is the consistency index and $\mathrm{n}$ is the flow behavior index:

$$
\sigma=\mathrm{K} \dot{\gamma}^{\mathrm{n}}
$$

\section{Color Measurements}

Color was measured in a Konica Minolta CM-3500d colorimeter (Konica Minolta Business Technologies Inc., Tokyo, Japan). A 3.5-cm thick layer of sample was contained in optical glass cells $3.8 \mathrm{~cm}$ high and $6 \mathrm{~cm}$ in diameter to measure diffused reflected light from the cell bottom using an $8 \mathrm{~mm}$ diaphragm aperture. Results were given using the CIELAB system for illuminant D 65 and a $10^{\circ}$ angle of vision. Registered parameters were $\mathrm{L}^{*}$ (brightness), $\mathrm{a}^{*}$ (red component), $\mathrm{b}^{*}$ (yellow component), $\mathrm{C}^{*}$ (chroma), and $\mathrm{h}^{*}$ (hue). Two batches of each composition were prepared and 3 measurements were performed on each batch.

\section{Soluble Solids Content}

Soluble solids content was determined with a digital refractometer (R-X 1000 model, Pal-1 Atago Co. Ltd.,
Tokyo, Japan) and expressed in degrees Brix. Two batches of each composition were prepared and 3 measurements were performed on each batch.

\section{Sensory Analysis}

Descriptor Selection and Training. An initial list of terms was prepared with the information obtained from previous laboratory studies (González-Tomás and Costell, 2006b; Tárrega and Costell, 2006) and from other research groups (De Wijk et al., 2003). Twelve assessors with previous experience (more than $3 \mathrm{yr}$ ) in evaluating sensory differences in different dairy products, including dairy desserts, were asked to evaluate the suitability of these descriptors to describe the sensory characteristics of the samples according to the checklist method (Damasio and Costell, 1991). The initial list, composed of 21 terms regarding the appearance, odor, flavor, and texture of the samples, was finally reduced to 18 after the training sessions with the assessors. The final list of descriptors, their end terms, and definitions are shown in Table 1.

Assessors were trained in 3 sessions according to the guidelines of the ISO (1993). The first session was held with the panel leader and all of the assessors and was intended to select and define the descriptors, to determine the sample evaluation procedures, and establish the definitive scorecard. In the other 2 sessions, each assessor evaluated the intensity of the 18 previously selected attributes in separate booths on 3 different com- 
mercial samples. At the end of these sessions, the panel leader and assessors discussed the individual results obtained to establish consensus criteria for evaluation.

Descriptive Profile. Descriptive analysis of the 8 samples was carried out in duplicate over 4 sessions and each assessor evaluated 4 samples per session (Meilgaard et al., 1991). Samples (40 mL) were served at 10 $\pm 1^{\circ} \mathrm{C}$ in covered white plastic vessels coded with 3 -digit random numbers. For each sample, odor attributes were evaluated first. Then, assessors were asked to evaluate the appearance, flavor, and finally, texture attributes. Still mineral water was used as palate cleanser. The intensity of each attribute was scored on a nonstructured $10-\mathrm{cm}$ scale, with the corresponding end terms (Table 1). To reduce the influence of serving order, the samples evaluated in each session were served following a Williams design for 4 samples in balanced blocks of 12 assessors. Samples were presented monadically. All sessions were carried out in a standardized test room with separate booths under normal white fluorescent illumination in morning sessions (1100 to 1300 h). Experimental design, data acquisition, and analysis were performed using Compusense Five, release 4.6 (Compusense Inc., Guelph, ON, Canada).

\section{Statistical Analysis}

A 2-way ANOVA (type of milk and type of inulin) with interaction was applied to the color and rheological data. Tukey's test $(\alpha=0.05)$ was used to calculate the minimum significant difference. A 2-way ANOVA (samples and assessors) with interaction was applied to the sensory data obtained for each attribute. Individual differences between assessors were analyzed by a fixed model, considering assessors as fixed factor. When a significant interaction between assessors and sample was observed for a descriptor, a mixed model ANOVA, considering assessors as random effect, was performed (Carlucci and Monteleone, 2001). $\mathrm{F}_{\text {sample }}$ values were then recalculated taking the average square of the interaction as denominator. Minimum significant differences were calculated by the Fisher's test $(\alpha=0.05)$. Finally, another 2-way ANOVA (type of milk and type of inulin) with interaction was applied to the sensory data to determine the effect of the milk type and inulin type on odor, appearance, flavor, and texture attributes. Minimum significant differences were calculated by the Tukey's test $(\alpha=0.05)$. Principal component analysis with varimax rotation was also applied to the mean values of attribute intensity. All calculations were carried out with XLSTAT Pro software, version 2007 (Addinsoft, Paris, France).

\section{RESULTS AND DISCUSSION}

\section{Physicochemical Properties}

Color Measurements. Figure 1 shows the reflectance spectra in the visible region (400 to $700 \mathrm{~nm}$ ) obtained for the 8 samples analyzed. All of them displayed the typical spectral curve for yellow-orange colored materials with maximum reflectance values at wavelengths longer than $550 \mathrm{~nm}$. In addition, a slight decrease in the reflectance percentage values was observed in skim milk samples at wavelength values above $570 \mathrm{~nm}$. Whole milk samples clearly showed higher percentages of reflected light than skim milk samples. The ANOVA gave differences $(P \leq 0.05)$ between samples for the values of the 5 color parameters. Milk type significantly affected all color parameters. Brightness $\left(\mathrm{L}^{*}\right)$, redness $\left(a^{*}\right)$, yellowness $\left(b^{*}\right)$, and saturation $\left(\mathrm{C}^{*}\right)$ values were higher for whole milk samples, whereas hue $\left(\mathrm{h}^{*}\right)$ values were higher for skim milk samples (Table 2). In general, whole milk samples were the lighter colored ones and showed a stronger yellow-orange color. The average chain length of the added inulin significantly affected brightness values but no other parameter. Samples with long-chain inulin and without inulin were the lighter colored ones.

Soluble Solids Content Measurement. The samples containing skim milk presented, in general, similar soluble solids content compared with wholemilk samples. Samples without inulin had lower soluble solids content $\left(22.2 \pm 0.5\right.$ and $22.0 \pm 0.2^{\circ} \mathrm{Bx}$ for whole and skim milk samples, respectively) than samples containing this polysaccharide. As expected, because of the chemical nature of the different inulins, the samples containing short-chain inulin (7-9 monomers, 10-14\% of sugars) presented slightly higher soluble solids content $\left(29.0 \pm 0.1\right.$ and $29.3 \pm 0.1^{\circ} \mathrm{Bx}$ for whole and skimmilk samples, respectively) than samples with native inulin (9-12 monomers, $5-10 \%$ of sugars; $28.7 \pm 0.2$ and $28.9 \pm 0.2^{\circ} \mathrm{Bx}$ for whole and skim-milk samples, respectively), and the latter gave higher values than the samples with long-chain inulin $(\geq 23$ monomers, $0.5 \%$ of sugars; $26.8 \pm 0.3$ and $27.2 \pm 0.2^{\circ} \mathrm{Bx}$ for whole and skim-milk samples, respectively).

Flow Behavior. Figure 2 shows the flow curves for samples without inulin and with different types of inulin formulated with both whole and skim milks. All samples showed observable hysteresis loops when they were sheared during a complete cycle, indicating that the samples' flow was time-dependent. The variation of the shear stress values with the shear rate indicated a non-Newtonian shear-thinning flow. This type of behavior is in accordance with that observed previously in 
Table 2. Mean values and significant differences of instrumental color parameters ${ }^{1}$ for dairy dessert samples with different composition

\begin{tabular}{lccccc}
\hline Sample & $\mathrm{L}^{*}$ & $\mathrm{a}^{*}$ & $\mathrm{~b}^{*}$ & $\mathrm{C}^{*}$ & $\mathrm{~h}^{*}$ \\
\hline Whole milk & & & & & \\
No inulin & $75.18^{\mathrm{a}}$ & $5.49^{\mathrm{a}}$ & $26.23^{\mathrm{ab}}$ & $26.80^{\mathrm{ab}}$ & $78.18^{\mathrm{b}}$ \\
Long-chain & $74.21^{\mathrm{ab}}$ & $5.30^{\mathrm{a}}$ & $26.90^{\mathrm{ab}}$ & $27.42^{\mathrm{ab}}$ & $78.85^{\mathrm{b}}$ \\
Native & $73.13^{\mathrm{ab}}$ & $5.44^{\mathrm{a}}$ & $27.39^{\mathrm{ab}}$ & $27.92^{\mathrm{a}}$ & $78.77^{\mathrm{b}}$ \\
Short-chain & $73.09^{\mathrm{b}}$ & $5.34^{\mathrm{a}}$ & $26.91^{\mathrm{ab}}$ & $27.44^{\mathrm{ab}}$ & $78.78^{\mathrm{b}}$ \\
Skim milk & & & & & \\
No inulin & $66.86^{\mathrm{c}}$ & $3.27^{\mathrm{b}}$ & $25.31^{\mathrm{b}}$ & $25.57^{\mathrm{b}}$ & $82.67^{\mathrm{a}}$ \\
Long-chain & $67.70^{\mathrm{c}}$ & $3.72^{\mathrm{b}}$ & $26.51^{\mathrm{ab}}$ & $26.77^{\mathrm{ab}}$ & $82.00^{\mathrm{a}}$ \\
Native & $66.31^{\mathrm{c}}$ & $3.42^{\mathrm{b}}$ & $25.84^{\mathrm{ab}}$ & $26.07^{\mathrm{ab}}$ & $82.47^{\mathrm{a}}$ \\
Short-chain & $66.02^{\mathrm{c}}$ & $3.45^{\mathrm{b}}$ & $25.65^{\mathrm{ab}}$ & $25.88^{\mathrm{b}}$ & $82.35^{\mathrm{a}}$ \\
\hline
\end{tabular}

${ }^{\mathrm{a}-\mathrm{c}}$ Means within a column with common superscripts did not differ significantly $(P<0.05)$.

${ }^{1} \mathrm{~L}^{*}=$ brightness; $\mathrm{a}^{*}=$ red component; $\mathrm{b}^{*}=$ yellow component; $\mathrm{C}^{*}=$ chroma; and $\mathrm{h}^{*}=$ hue.

semisolid dairy desserts (González-Tomás and Costell, 2006a). On visually comparing the hysteresis loops of samples made with both milk types (Figure 2), one can observe that the area is greater in the whole milk samples. This seems to confirm that, despite the average chain length of the inulin added, the structure of these systems is reinforced by the presence of the 3-dimensional fatty polymers (Tárrega and Costell, 2006).

Adding different types of inulin to milk starch dispersions gave rise to different flow behaviors. In skim milk systems, the flow was thixotropic in all cases (Figure 2a). In whole milk samples, adding the 3 types of inulin gave rise to combined hysteresis loops. At low deformation values, the behavior was antithixotropic, and at higher values, it was thixotropic. Figure $2 b$ shows that there was an antithixotropic response at shear stress values between 0 and $30 \mathrm{~Pa}$, approximately, and thixotropic behavior for higher deformation values. Other authors have reported combined hysteresis loops of aqueous starch pastes. Nayouf et al. (2003) observed

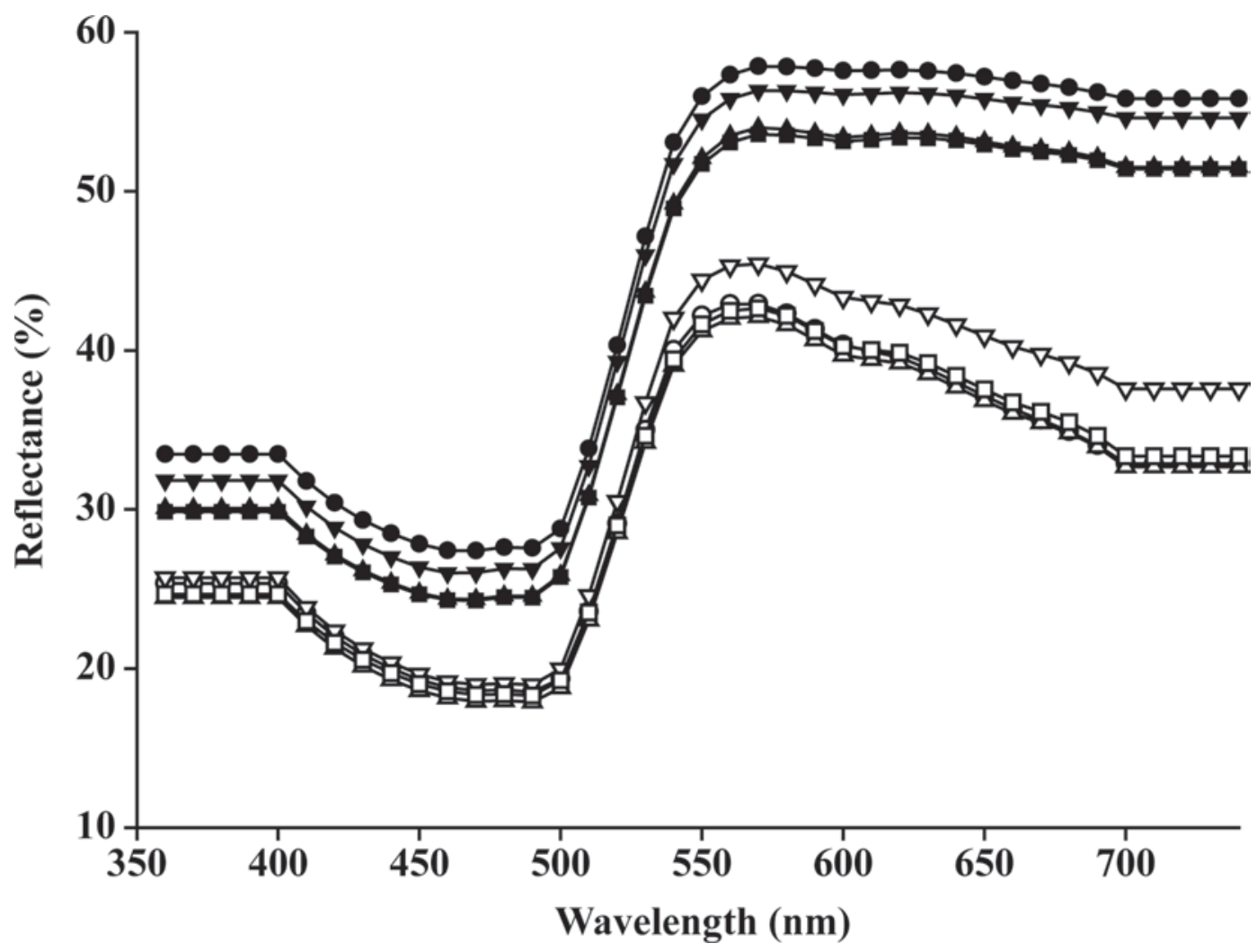

Figure 1. Spectral reflectance curves of skim milk (open symbols) and whole milk (solid symbols) samples without inulin $(\bigcirc)$ and containing different types of inulin ( $\Delta=$ native; $\square=$ short-chain; $\nabla=$ long-chain inulin). 
a

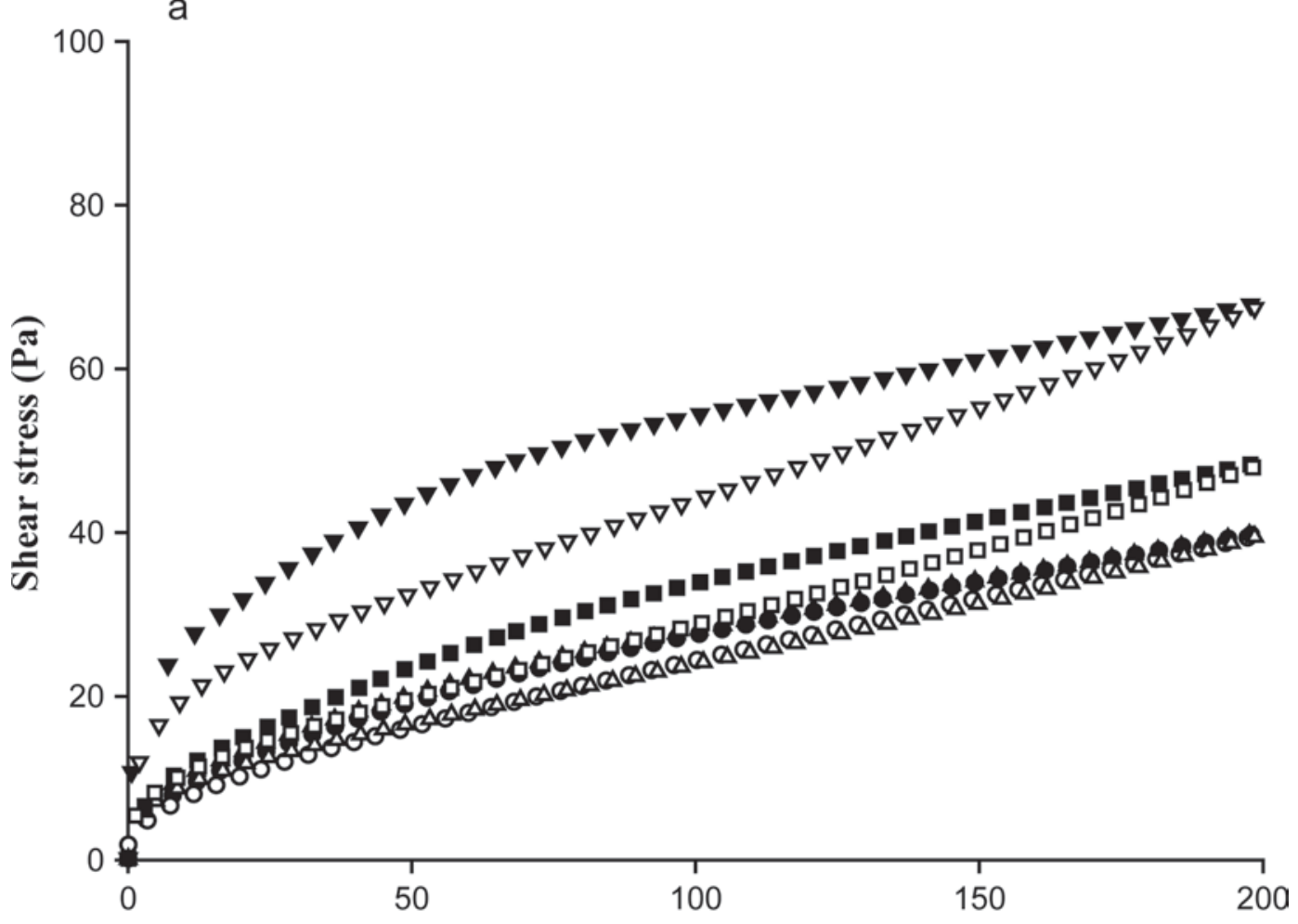

b

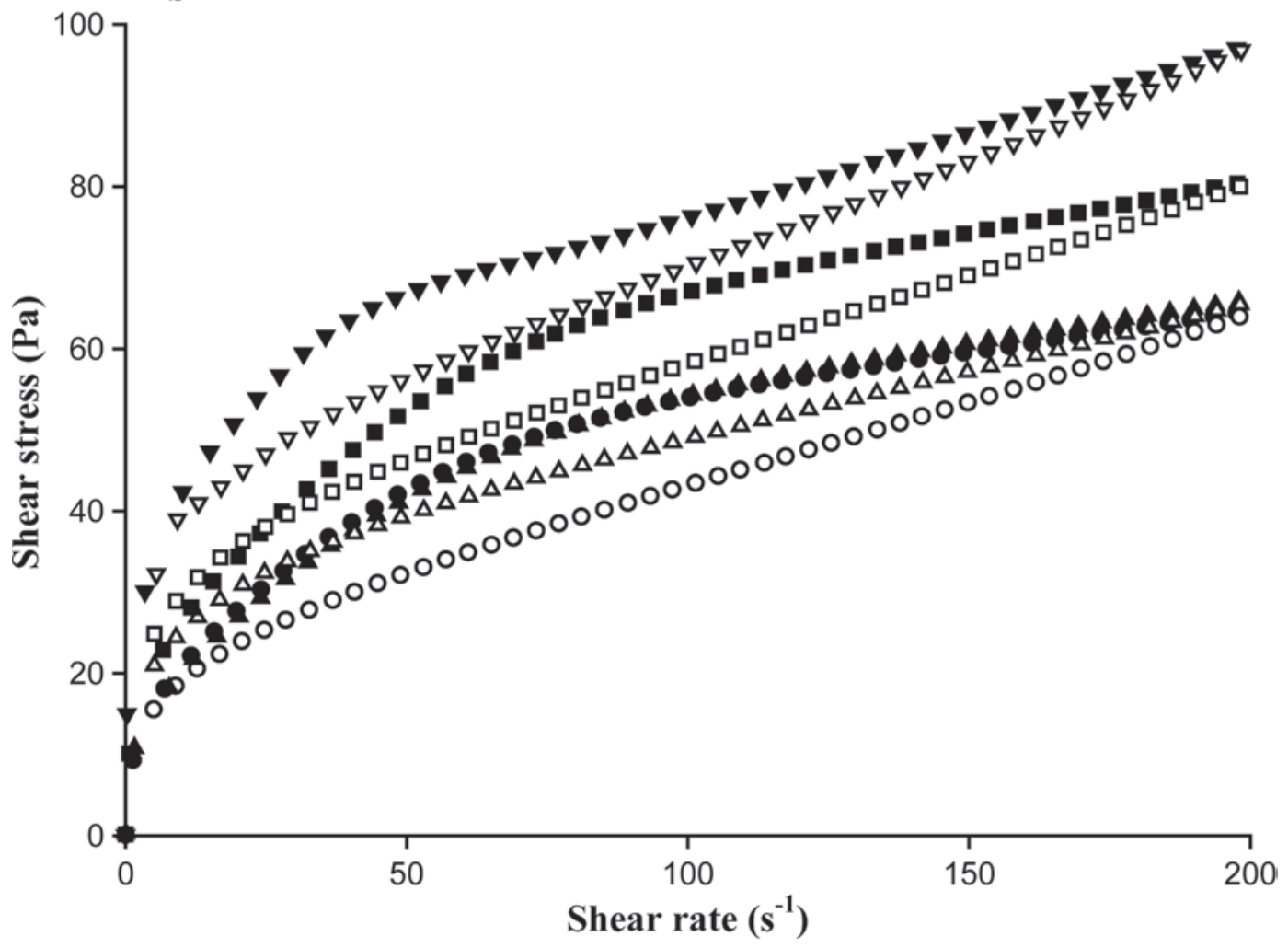

Figure 2. Flow curves of skim milk (a) and whole milk (b) samples without inulin $(\bigcirc)$ and containing different types of inulin $(\Delta=$ native; $\square=$ short-chain; $\nabla=$ long-chain inulin). Shear stress experimental values obtained from upward (solid symbols) and downward (open symbols) curve. 
antithixotropic behavior in the flow of cross-linked waxy cornstarch pastes. Those authors speculated that antithixotropic behavior would be explained by a rearrangement of the starch granules, enhanced by shearing. The presence of antithixotropy in the starchpaste flow reflects the creation of a structure induced by shearing. When the pastes are of modified starches, antithixotropy can be caused by the formation of aggregates or groups of granules by the effect of shearing and is closely related to the extent of the deformation imposed on the system. The shear stress values at which the change takes place between both types of behavior (thixotropic and antithixotropic) are specific to each starch type and oscillate between 10 and $150 \mathrm{~Pa}$ in accordance with Härröd (1989). In this case, the ascending and descending rheograms crossed at deformations close to $30 \mathrm{~Pa}$ (Figure $2 \mathrm{~b}$ ). In these systems, the fact that adding different types of inulin gives rise to antithixotropic flow may be because the inulin particles weaken the initial structure of the starch paste, with an effect similar to that of adding sugar, as reported by Acquarone and Rao (2003).

In addition to studying how adding different types of inulin affected the time dependency of flow in the analyzed samples, we also fitted the experimental data of ascending rheograms to the Ostwald de Waele model to compare the consistency $(\mathbf{K})$ and pseudoplasticity $(\boldsymbol{n})$ of the flow in the different systems. The fit was good in all cases, $\left(0.987<\mathrm{R}^{2}<0.998\right)$. The flow index values varied between 0.27 and 0.51 . The range of variation in $n$ was greater in the flow of the skim-milk samples (0.31 to 0.51$)$ than in whole-milk samples ( 0.27 to 0.37 ). All the whole-milk samples gave higher values on the consistency index and lower ones on the flow index than the equivalent samples made with skim milk (Figure 3).

Results from ANOVA showed that both type of milk and type of inulin affected flow parameter values $(P$ $<0.05)$ and that there was a significant effect of the interaction between them on the values of $\mathrm{K}$ and $n$ ( $P$ $<0.05)$. This interaction indicated that the effect of inulin type on these variables differed depending on the type of milk. The variation of $\mathrm{K}$ values based on inulin type was greater in skim-milk samples compared with whole-milk samples (Figure 3a). In both types of milk, the samples with long-chain inulin were the most consistent $(P<0.05)$, whereas addition of the other 2 inulins had a much smaller effect. One can observe that the consistency index value of the skim-milk sample with added long-chain inulin did not differ significantly from that of the whole-milk sample without added inulin (Figure 3a). This result agrees with that obtained previously by Tárrega and Costell (2006) when studying the effect of long-chain inulin addition $(6 \% \mathrm{wt} / \mathrm{wt})$ on the rheological behavior of fat-free dairy desserts. No significant differences between whole milk and inulinskim milk samples were observed for samples with a $3.25 \%$ starch concentration by these authors. Similarly, adding long-chain inulin to skim-milk samples modified the pseudoplasticity of the flow to a greater extent than those observed in whole-milk samples. In both types of milk, pseudoplasticity clearly increased when long-chain inulin was added (Figure 3b). As stated by Kaur and Gupta (2002), long-chain inulin can form microcrystals. Thus, the clear increase observed in the consistency index of samples with long-chain inulin could be attributed to the exclusion effect of the starch, which would lead to the formation of aggregates containing inulin crystals. These aggregates would retain large amounts of liquid phase and would increase the volume fraction of the dispersed phase (Bot et al., 2004). The addition of native and short-chain inulin hardly modified the pseudoplasticity and consistency of the samples but, on adding long-chain inulin there was a clear increase in pseudoplasticity and consistency.

\section{Sensory Properties}

A fixed model of 2-way ANOVA (samples and assessors) with interaction (Table 3) was applied to the sensory scores obtained for the 18 attributes evaluated. Significant differences between samples $(\alpha=0.05)$ were detected except for 4 attributes: milk odor, cinnamon odor, off odor, and off flavor. Assessors were also a significant source of variation in all cases. This was not surprising because it is well known that, in spite of the selection and training of judges, some variability always remains (Naes, 1990). However, it is important to know whether the assessor's variability may influence the estimation of sample differences. The significance of the effect of sample $\times$ assessor interaction provides information about this point (Carlucci and Monteleone, 2001). In this case, with regard to the 14 attributes for which the panel found significant perceptible differences $(\alpha=0.05)$ among samples, the effect of the interaction sample $\times$ assessor was not significant $(P>0.05)$ for 8 of them, indicating a good level of concordance among the panel members on their evaluations. For the remaining 6 attributes (vanilla odor, color shade, milk flavor, after taste, roughness, and mouth coating), the sample $\times$ assessor interaction was significant $(P \leq$ 0.05) indicating a certain lack of concordance within the panel. In spite of this, the main sample effect for these 6 attributes remained significant when a mixed model of ANOVA was applied considering assessors as random effect (Table 3 ).

The mean values of the 14 sensory attributes for each sample and the significant differences among them (Ta- 


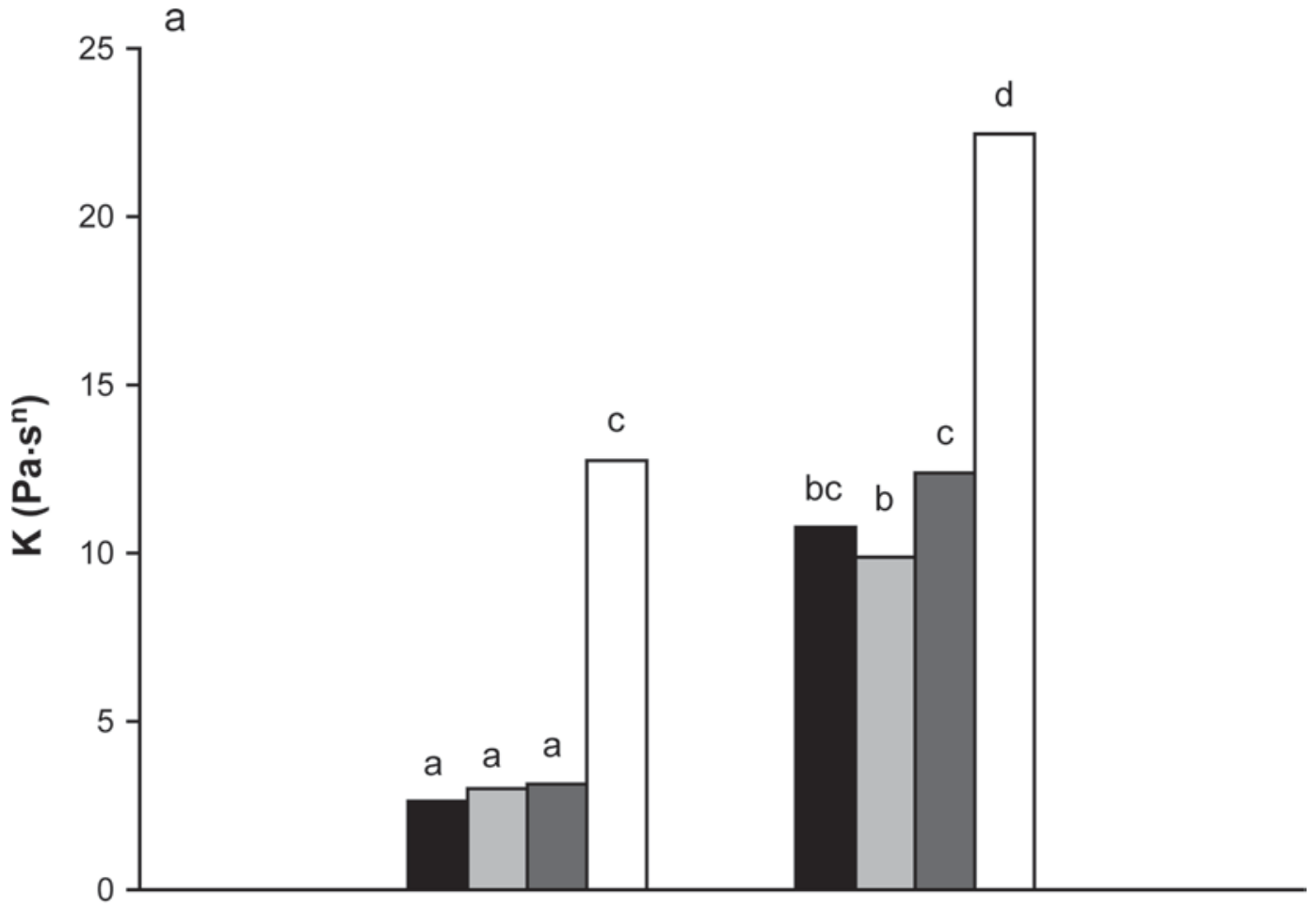

Skim milk Whole milk

b

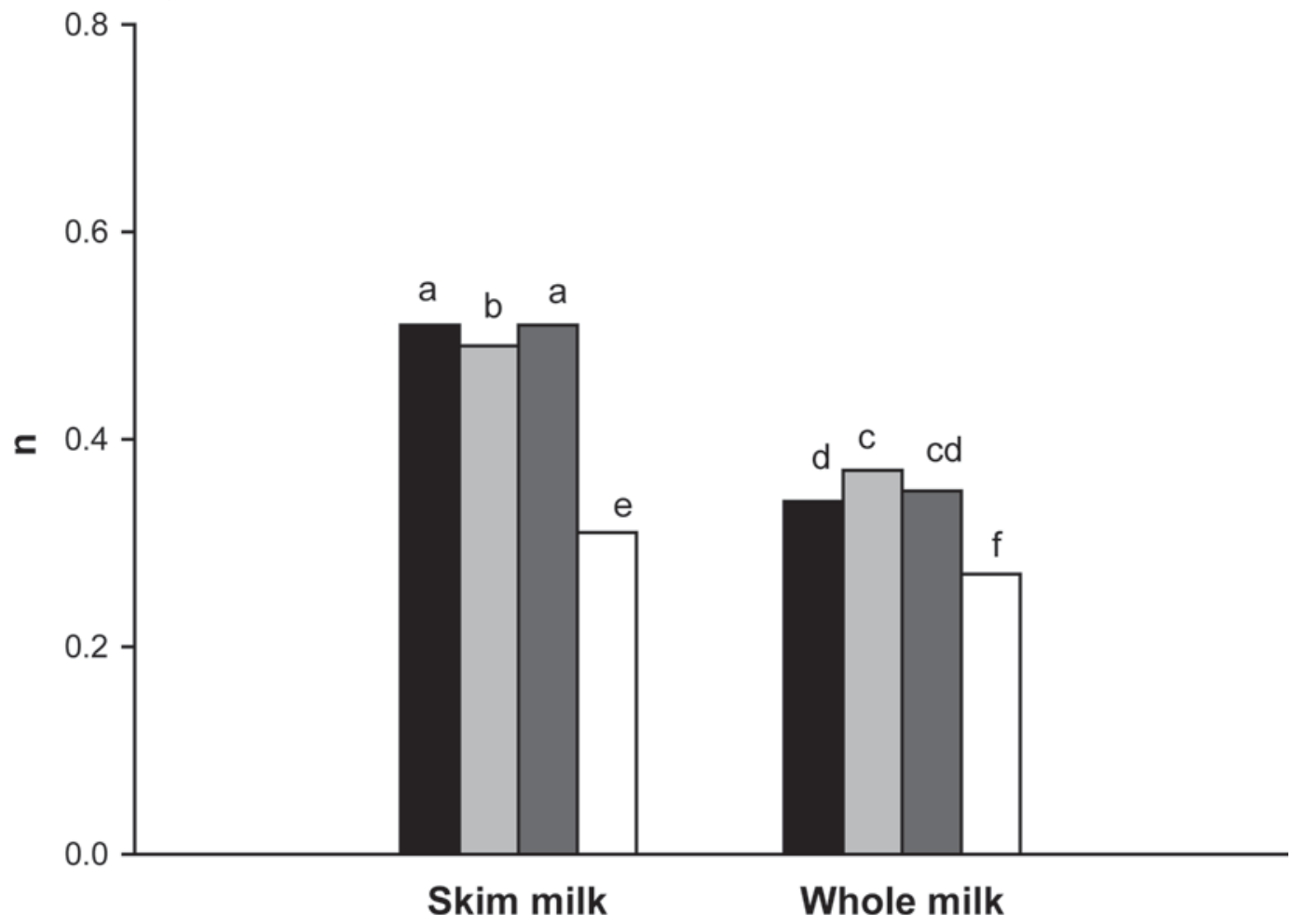

Figure 3. Consistency index values (a; K) and flow index values (b; $n$ ) of whole milk and skim milk samples without inulin (black) and containing native (light gray), short-chain (dark gray), and long-chain inulin (white). In each graph, different letters above bars denote significant differences between samples $(\alpha=0.05)$. 
Table 3. Two-way ANOVA of sensory attributes (12 assessors, 8 samples, 2 repetitions $)^{1}$

\begin{tabular}{|c|c|c|c|c|c|}
\hline Category & Attribute & Sample $^{2}$ & Assessor & $\begin{array}{c}\text { Sample } \times \\
\text { assessor }\end{array}$ & Sample $^{3}$ \\
\hline \multirow[t]{5}{*}{ Odor } & Odor intensity & $4.44^{*}$ & $5.66^{*}$ & $1.17^{\mathrm{NS}}$ & - \\
\hline & Vanilla odor & $7.31^{*}$ & $10.13^{*}$ & $1.87^{*}$ & $3.92 *$ \\
\hline & Milk odor & $1.63^{\mathrm{NS}}$ & $7.34^{*}$ & $1.01^{\mathrm{NS}}$ & - \\
\hline & Cinnamon odor & $1.74^{\mathrm{NS}}$ & $3.11^{*}$ & $0.79^{\mathrm{NS}}$ & - \\
\hline & Off odor & $1.28^{\mathrm{NS}}$ & $13.02^{*}$ & $1.01^{\mathrm{NS}}$ & - \\
\hline \multirow[t]{3}{*}{ Appearance } & Color intensity & $22.14^{*}$ & $8.94^{*}$ & $0.86^{\mathrm{NS}}$ & - \\
\hline & Color shade & $15.13^{*}$ & $11.64^{*}$ & $1.55^{*}$ & $9.79^{*}$ \\
\hline & Visual consistency & $59.85^{*}$ & $9.76^{*}$ & $1.04^{\mathrm{NS}}$ & - \\
\hline \multirow[t]{6}{*}{ Flavor } & Flavor intensity & $6.27^{*}$ & $4.34^{*}$ & $1.02^{\mathrm{NS}}$ & - \\
\hline & Sweetness & $6.32^{*}$ & $6.39^{*}$ & $0.83^{\mathrm{NS}}$ & - \\
\hline & Vanilla flavor & $9.17^{*}$ & $16.55^{*}$ & $0.93^{\mathrm{NS}}$ & - \\
\hline & Milk flavor & $9.34^{*}$ & $8.02^{*}$ & $1.67^{*}$ & $5.59^{*}$ \\
\hline & Off flavor & $1.07^{\mathrm{NS}}$ & $4.89^{*}$ & $1.12^{\mathrm{NS}}$ & - \\
\hline & After taste & $4.49^{*}$ & $16.93^{*}$ & $1.50^{*}$ & $2.99^{*}$ \\
\hline \multirow[t]{4}{*}{ Texture } & Consistency in mouth & $30.16^{*}$ & $6.56^{*}$ & $0.96^{\mathrm{NS}}$ & - \\
\hline & Creaminess & $7.77^{*}$ & $6.03^{*}$ & $1.22^{\mathrm{NS}}$ & - \\
\hline & Roughness & $112.29^{*}$ & $15.89^{*}$ & $2.2^{*}$ & $51.00^{*}$ \\
\hline & Mouth coating & $4.30 *$ & $6.93^{*}$ & $1.45^{*}$ & $2.96^{*}$ \\
\hline
\end{tabular}

ble 4) enabled the perceived differences to be analyzed. To obtain information about the influence of composition on sensory attributes intensity, a new 2-way ANOVA with interaction was applied to the sensory data to determine the effects of milk type and of inulin type on odor, appearance, flavor, and texture attributes. The effect of the milk type $\times$ inulin type interaction was nonsignificant for all 14 attributes (Table 5) indicating that the effect of adding inulins with different average chain length follows a similar trend for the samples prepared with both milk types. Attributes can be grouped by the effect of each of the 2 ingredients, according to the results shown in Table 5 .

Attributes Affected Only by Type of Milk. Perceptible differences in odor intensity, vanilla odor, color intensity, color shade, vanilla flavor, milk flavor, and creaminess were due only to the type of milk. For each group of samples; that is, whole or skim milk samples,

Table 4. Mean values of sensory attributes scores and corresponding Fisher's significant difference for the eight samples

\begin{tabular}{|c|c|c|c|c|c|c|c|c|}
\hline \multirow[b]{2}{*}{ Attribute $^{1}$} & \multicolumn{4}{|c|}{ Whole milk } & \multicolumn{4}{|c|}{ Skim milk } \\
\hline & No inulin & Long-chain & Native & Short-chain & No inulin & Long-chain & Native & Short-chain \\
\hline \multicolumn{9}{|l|}{ Odor } \\
\hline Odor intensity & $4.61^{\mathrm{ab}}$ & $3.99^{\mathrm{b}}$ & $4.32^{\mathrm{b}}$ & $4.45^{\mathrm{ab}}$ & $5.93^{\mathrm{ab}}$ & $5.21^{\mathrm{ab}}$ & $5.88^{\mathrm{ab}}$ & $6.37^{\mathrm{a}}$ \\
\hline Vanilla odor & $3.26^{\mathrm{b}}$ & $3.66^{\mathrm{ab}}$ & $3.41^{\mathrm{ab}}$ & $3.78^{\mathrm{ab}}$ & $5.23^{\mathrm{a}}$ & $5.04^{\mathrm{ab}}$ & $5.35^{\mathrm{a}}$ & $5.35^{\mathrm{a}}$ \\
\hline \multicolumn{9}{|l|}{ Appearance } \\
\hline Color intensity & $2.69^{\mathrm{b}}$ & $3.38^{\mathrm{b}}$ & $3.45^{\mathrm{b}}$ & $3.12^{\mathrm{b}}$ & $5.78^{\mathrm{a}}$ & $5.80^{\mathrm{a}}$ & $5.82^{\mathrm{a}}$ & $5.36^{\mathrm{a}}$ \\
\hline Color shade & $2.57^{\mathrm{b}}$ & $2.61^{\mathrm{b}}$ & $3.17^{\mathrm{ab}}$ & $3.43^{\mathrm{ab}}$ & $4.90^{\mathrm{a}}$ & $5.15^{\mathrm{a}}$ & $5.13^{\mathrm{a}}$ & $4.79^{\mathrm{a}}$ \\
\hline Visual consistency & $4.47^{\mathrm{b}}$ & $7.91^{\mathrm{a}}$ & $4.72^{\mathrm{b}}$ & $5.41^{\mathrm{b}}$ & $1.80^{\mathrm{c}}$ & $4.75^{\mathrm{b}}$ & $2.46^{\mathrm{c}}$ & $2.42^{\mathrm{c}}$ \\
\hline \multicolumn{9}{|l|}{ Flavor } \\
\hline Flavor intensity & $6.26^{\mathrm{b}}$ & $6.12^{\mathrm{b}}$ & $6.24^{\mathrm{b}}$ & $7.62^{\mathrm{a}}$ & $6.39^{\mathrm{ab}}$ & $7.14^{\mathrm{ab}}$ & $7.51^{\mathrm{ab}}$ & $7.89^{\mathrm{a}}$ \\
\hline Sweetness & $5.58^{\mathrm{ab}}$ & $5.32^{\mathrm{b}}$ & $6.10^{\mathrm{ab}}$ & $6.86^{\mathrm{ab}}$ & $6.64^{\mathrm{ab}}$ & $6.32^{\mathrm{ab}}$ & $7.32^{\mathrm{ab}}$ & $7.56^{\mathrm{a}}$ \\
\hline Vanilla flavor & $4.23^{\mathrm{c}}$ & $4.22^{\mathrm{c}}$ & $4.63^{\mathrm{bc}}$ & $4.60^{\mathrm{c}}$ & $6.21^{\mathrm{ab}}$ & $5.62^{\mathrm{ab}}$ & $6.67^{\mathrm{a}}$ & $6.46^{\mathrm{a}}$ \\
\hline Milk flavor & $5.48^{\mathrm{a}}$ & $5.18^{\mathrm{a}}$ & $4.77^{\mathrm{ab}}$ & $5.79^{\mathrm{a}}$ & $4.23^{\mathrm{ab}}$ & $3.88^{\mathrm{ab}}$ & $2.76^{\mathrm{b}}$ & $3.78^{\mathrm{ab}}$ \\
\hline After taste & $3.60^{\mathrm{a}}$ & $4.18^{\mathrm{a}}$ & $3.80^{\mathrm{a}}$ & $4.18^{\mathrm{a}}$ & $2.44^{\mathrm{a}}$ & $4.70^{\mathrm{a}}$ & $2.99^{\mathrm{a}}$ & $3.51^{\mathrm{a}}$ \\
\hline \multicolumn{9}{|l|}{ Texture } \\
\hline Consistency in mouth & $4.96^{\mathrm{cd}}$ & $7.86^{\mathrm{a}}$ & $5.17^{\mathrm{bc}}$ & $6.32^{\mathrm{b}}$ & $2.58^{\mathrm{e}}$ & $5.98^{\mathrm{bc}}$ & $3.29^{\mathrm{e}}$ & $3.79^{\mathrm{de}}$ \\
\hline Creaminess & $6.65^{\mathrm{ab}}$ & $7.15^{\mathrm{a}}$ & $7.28^{\mathrm{a}}$ & $7.42^{\mathrm{a}}$ & $5.43^{\mathrm{b}}$ & $5.26^{\mathrm{b}}$ & $5.87^{\mathrm{ab}}$ & $5.90^{\mathrm{ab}}$ \\
\hline Roughness & $1.24^{\mathrm{b}}$ & $6.68^{\mathrm{a}}$ & $1.05^{\mathrm{b}}$ & $1.09^{\mathrm{b}}$ & $0.92^{\mathrm{b}}$ & $7.29^{\mathrm{a}}$ & $1.06^{\mathrm{b}}$ & $0.77^{\mathrm{b}}$ \\
\hline Mouth coating & $4.26^{\mathrm{ab}}$ & $5.21^{\mathrm{ab}}$ & $4.76^{\mathrm{ab}}$ & $4.87^{\mathrm{ab}}$ & $3.25^{\mathrm{b}}$ & $5.72^{\mathrm{a}}$ & $4.04^{\mathrm{ab}}$ & $4.82^{\mathrm{ab}}$ \\
\hline
\end{tabular}

${ }^{\mathrm{a}-\mathrm{e}}$ Means within a row with common superscripts did not differ significantly $(P<0.05)$.

${ }^{1}$ Attributes evaluated on a $10-\mathrm{cm}$, linear, semi-structured scale. 
Table 5. Two-way ANOVA with interaction of the sensory attributes ${ }^{1}$

\begin{tabular}{llccc}
\hline Category & Attribute & Milk type & Inulin type & $\begin{array}{c}\text { Milk type } \times \\
\text { inulin type }\end{array}$ \\
\hline Odor & Odor intensity & $36.55^{*}$ & $2.00^{\mathrm{NS}}$ & $0.39^{\mathrm{NS}}$ \\
& Vanilla odor & $48.78^{*}$ & $0.30^{\mathrm{NS}}$ & $0.34^{\mathrm{NS}}$ \\
Appearance & Color intensity & $263.73^{*}$ & $1.97^{\mathrm{NS}}$ & $1.48^{\mathrm{NS}}$ \\
& Color shade & $64.72^{*}$ & $0.59^{\mathrm{NS}}$ & $1.02^{\mathrm{NS}}$ \\
Flavor & Visual consistency & $144.15^{*}$ & $38.25^{*}$ & $0.72^{\mathrm{NS}}$ \\
& Flavor intensity & $8.32^{*}$ & $7.01^{*}$ & $1.42^{\mathrm{NS}}$ \\
& Sweetness & $14.03^{*}$ & $5.48^{*}$ & $0.17^{\mathrm{NS}}$ \\
& Vanilla flavor & $79.92^{*}$ & $2.57^{\mathrm{NS}}$ & $0.51^{\mathrm{NS}}$ \\
\multirow{2}{*}{ Texture } & Milk flavor & $29.96^{*}$ & $2.78^{\mathrm{NS}}$ & $0.49^{\mathrm{NS}}$ \\
& After taste & $2.97^{\mathrm{NS}}$ & $3.97^{\mathrm{NS}}$ & $1.42^{\mathrm{NS}}$ \\
& Consistency in mouth & $194.01^{*}$ & $79.60^{*}$ & $1.17^{\mathrm{NS}}$ \\
& Creaminess & $28.20^{*}$ & $1.08^{\mathrm{NS}}$ & $0.25^{\mathrm{NS}}$ \\
& Roughness & $0.00^{\mathrm{NS}}$ & $87.71^{*}$ & $0.47^{\mathrm{NS}}$ \\
& Mouth coating & $1.35^{\mathrm{NS}}$ & $7.06^{*}$ & $1.59^{\mathrm{NS}}$ \\
\hline
\end{tabular}

${ }^{1}$ Data are reported as $F$-values.

*Significant at $P<0.05 ; \mathrm{NS}=$ not significant

no significant differences on these attributes were found between the control sample (without inulin) and the samples with inulin (Table 4). Whole milk samples gave lower values for these attributes than skim milk samples, except for the milk flavor and creaminess attributes. Whole milk samples were perceived to have a milkier and creamier flavor than skim milk samples.

Attributes Affected Only by Type of Inulin. Differences perceived in roughness and in mouth coating were due only to differences in average chain length of the inulin added. In both milk types, roughness intensity was significantly enhanced by addition of longchain inulin, but was not affected by short-chain or native inulin addition. Perception of mouth coating for whole milk samples was not affected by the addition of inulins with different average chain length. In the case of skim milk samples, a significant increase in mouth coating intensity was observed when long-chain inulin was added.

As stated previously, roughness intensity was significantly enhanced by the addition of long-chain inulin in both milk types (Table 4). This effect could be due to small crystals or crystal aggregates of long-chain inulin in the product that influence the sensory characteristics of the samples. Some authors have reported on the particle size of inulin crystals, whereas others have discussed the effects that adding different sized particles may have on the sensory characteristics of dairy matrices, similar to those of the samples analyzed in this paper. Hébette et al. (1998) described the complex melting and crystalline behavior of an aqueous suspension of inulin crystallites. They observed the presence of inulin crystallites shaped like the number 8 with particle size from 5 to 20 $\mu \mathrm{m}$ by optical microscopy. Kim et al. (2001) also found differences in inulin particle sizes between low shearing, high shearing, and thermally induced gels. The average particle size of inulin crystals varied from $30 \mu \mathrm{m}$ for low-shear induced gel to approximately $2 \mu \mathrm{m}$ for thermally induced gels. Therefore, inulin crystals with a particle size from 2 to $30 \mu \mathrm{m}$ could be expected. Engelen et al. (2005) investigated the effect of size (2 to 230 $\mu \mathrm{m}$ ) and type (silica dioxide and polystyrene spheres) of particles added to a carboxymethylcelluolose-based vanilla custard dessert on the perception of different sensory attributes. They observed that particle addition, even particles of $2 \mu \mathrm{m}$, increased the sensation of roughness and decreased smoothness. In addition, the particle size effect increased with increasing particle size up to $80 \mu \mathrm{m}$ and roughness ratings decreased for larger particles sizes. According to this information, the increase in roughness perceived for both the whole and skim milk samples with added long-chain inulin could be explained by the presence of inulin crystals.

Attributes Affected by Both Type of Milk and Type of Inulin. For the other attributes, differences perceived in the visual and in-mouth consistency, flavor intensity, and sweetness were affected by both milk type and inulin type (Table 5). As expected, whole milk samples were perceived to have more visual and in-mouth consistency than skim milk samples. As in the case of roughness, for each milk type, differences perceived in these attributes were due only to differences in the average chain length of the added inulin (Table 4). The addition of short-chain or native inulin did not significantly modify the intensity of these attributes and both attributes were enhanced by addition of long-chain inulin. One can observe that the visual and in-mouth consistency intensity of skim-milk samples with added long-chain inulin did not differ significantly in the intensity of these attributes compared with whole 


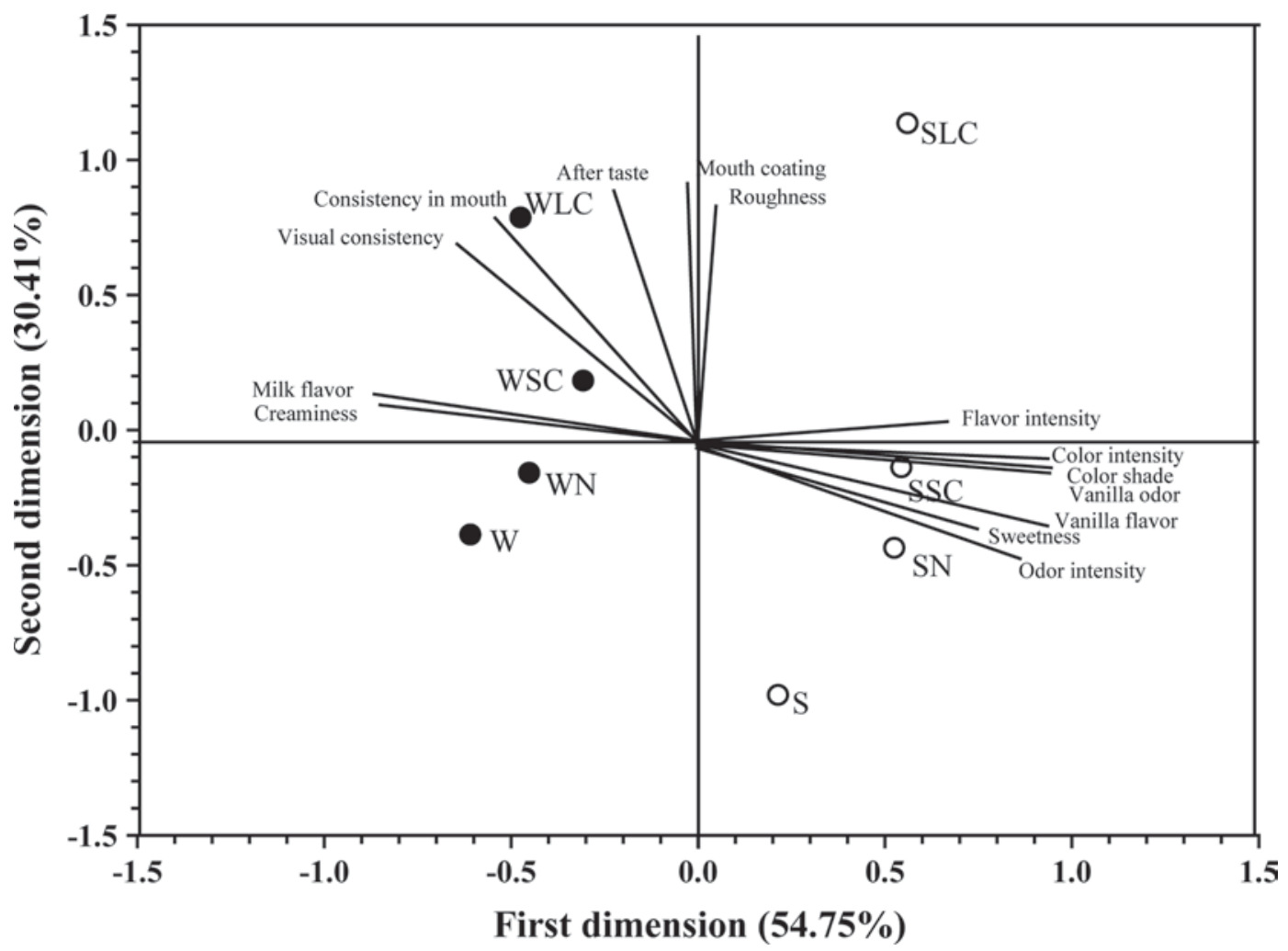

Figure 4. Principal component analysis bi-plot of the samples evaluated $(\mathrm{S}=$ skim milk; $\mathrm{W}=$ whole milk; $\mathrm{N}=$ native inulin; $\mathrm{SC}=$ shortchain inulin; $\mathrm{LC}=$ long-chain inulin).

milk samples without added inulin. These results are in concordance with the variation observed in consistency index values (Figure 3a). This confirms the suitability of long-chain inulin as a fat substitute in such dairy matrices, but also indicates that possible crystallization can give rise to unwanted attributes like roughness. In general, skim milk samples were perceived to have more flavor and more sweetness intensity than whole milk samples, reflecting the effect of fat on flavor and even the effect of consistency (Bayarri et al., 2007). Furthermore, for both milk types, samples containing short-chain inulin were perceived to have more intensity of flavor and sweetness (Table 4) as expected because of its higher soluble solids content.

To study the joint variability of the attributes for which significant differences were found, principal component analysis was applied to average scores of all attributes (Figure 4). The differences between the samples on the first axis are linked mainly to the variation in intensity of the attributes that depend primarily on the milk type, whereas the differences on the second axis are linked to the attributes for which the presence of different types of inulin exert an important influence. The first component explained $54.75 \%$ of total variability and clearly separated the whole milk samples from the skim milk samples. Whole milk samples, in the negative part of the first dimension, showed higher milk flavor intensity, more creaminess, and greater consistency. Skim milk samples, in the positive part of the first dimension, were evaluated to have greater color intensity, stronger odor and flavor intensity, and be sweeter. The second component explained 30.41\% of total variability and was defined mainly by textural attributes. On the positive side, we have the samples with long-chain inulin, which are the most consistent but rough; on the negative side, we have the sample prepared with skim milk and without added inulin, which is the least consistent and without perceptible roughness.

\section{CONCLUSIONS}

The results have shown that the effect of adding 7.5\% inulin of different average chain length can give rise to products with different rheological behavior and different sensory characteristics. The skim milk sample with long-chain inulin and whole milk sample without inulin showed similar flow behavior. Both samples were perceived to have the same creaminess and consistency intensity, but long-chain inulin addition increased 
roughness intensity and consequently its sensory quality could be negatively affected. The information obtained may be of great interest in designing new products with nutritional and sensory characteristics that meet consumer demands.

\section{ACKNOWLEDGMENTS}

The authors acknowledge the Instituto Danone for the fellowship awarded to author L. González, the Fondo Social Europeo for financing the contract of author S. Bayarri in the program I3P from Consejo Superior de Investigaciones Cientificas, and the Ministerio de Ciencia e Innovación of Spain for financial support (Project AGL 2007-63444). The authors also thank Chr. Hansen SA, Lucta SA, Sensus (Brenntag Química), and Central Lechera Asturiana SA for providing free samples of the ingredients.

\section{REFERENCES}

Acquarone, V. M., and M. A. Rao. 2003. Influence of sucrose on the rheology and granule size of cross-linked waxy maize starch dispersions heated at two temperatures. Carbohydr. Polym. $51: 451-458$.

Bayarri, S., T. Smith, T. Hollowood, and J. Hort. 2007. The role of rheological behaviour in flavour perception in model oil/water emulsions. Eur. Food Res. Technol. 226:161-168.

Bot, A., U. Erle, R. Vreeker, and W. G. M. Agterof. 2004. Influence of crystallisation conditions on the large deformation rheology of inulin gels. Food Hydrocoll. 18:547-556.

Cardarelli, H. R., F. C. A. Buriti, I. A. Castro, and S. M. I. Saad. 2008. Inulin and oligofructose improve sensory quality and increase the probiotic viable count in potentially symbiotic Petit-Suisse cheese. Lebensm. Wiss. Technol. 41:1037-1046.

Carlucci, A., and E. Monteleone. 2001. Statistical validation of sensory data: A study on wine. J. Sci. Food Agric. 81:751-758.

Clydesdale, F. 2004. Functional foods: Opportunities and challenges. Food Technol. 58:35-40.

Coussement, P. A. A. 1999. Inulin and oligofructose: Safe intakes and legal status. J. Nutr. 129:1412S-1417S.

Damasio, M. H., and E. Costell. 1991. Descriptive sensory analysis. Generation of descriptors and selection of judges. Rev. Agroquím. Tecnol. Aliment. 31:165-178.

De Wijk, R. A., L. J. van Gemert, M. E. J. Terpstra, and C. L. Wilkinson. 2003. Texture of semi-solids; Sensory and instrumental measurements on vanilla custard desserts. Food Qual. Prefer. 14:305-307.

Engelen, L., R. A. de Wijk, A. van der Bilt, J. F. Prinz, A. M. Janssen, and F. Bosman. 2005. Relating particles and texture perception. Physiol. Behav. 86:111-117.

Fogliano, V., and P. Vitaglione. 2005. Functional foods: Planning and development. Mol. Nutr. Food Res. 49:256-262.
Franck, A. 2002. Technological functionality of inulin and oligofructose. Br. J. Nutr. 87:S287-S291.

González-Tomás, L., J. Coll-Marqués, and E. Costell. 2008. Viscoelasticity of inulin-starch-based dairy systems. Influence of inulin average chain length. Food Hydrocoll. 22:1372-1380.

González-Tomás, L., and E. Costell. 2006a. Relation between consumer's perception of color and texture of dairy desserts and instrumental measurements using GPA. J. Dairy Sci. 89:4511-4519.

González-Tomás, L., and E. Costell. 2006b. Sensory evaluation of vanilla dairy desserts by repertory grid method and free-choice profile. J. Sens. Stud. 21:20-33.

Härröd, M. 1989. Time-dependent flow behaviour of starch pastes, with food process applications. J. Food Process Eng. 11:297-309.

Hébette, C. L. M., J. A. Delcour, M. H. J. Koch, K. Booten, R. Kleppinger, N. Mischenco, and H. Reynaers. 1998. Complex melting of semi-crystalline chicory (Cichoroum intybus L.) root inulin. Carbohydr. Res. 310:65-75

ISO. 1993. Sensory analysis. General guidance for the selection, training and monitoring of assessors. Part 1: Selected assessors. International Standard no. 8586. International Organization for Standardization, Winterthur, Switzerland.

Kaur, N., and A. K. Gupta. 2002. Applications of inulin and oligofructose in health and nutrition. J. Biosci. 27:703-714.

Kim, Y., M. N. Faqih, and S. S. Wang. 2001. Factors affecting gel formation of inulin. Carbohydr. Polym. 46:135-145.

Kip, P., D. Meyer, and R. H. Jellema. 2006. Inulins improve sensoric and textural properties of low-fat yoghurts. Int. Dairy J. 16:10981103.

Meilgaard, M., G. V. Civille, and B. T. Carr. 1991. Descriptive analysis techniques. Pages 161-172 in Sensory Evaluation Techniques. 3rd ed. CRC Press, New York, NY.

Naes, T. 1990. Handling individual differences between assessors in sensory profiling. Food Qual. Prefer. 2:187-199.

Nayouf, M., C. Loisel, and J. L. Doublier. 2003. Effect of thermomechanical treatment on the rheological properties of crosslinked waxy corn starch. J. Food Eng. 59:209-219.

Roberfroid, M., and J. Slavin. 2000. Nondigestible oligosaccharides. Crit. Rev. Food Sci. Nutr. 40:461-480.

Roberfroid, M. B. 2005. Introducing inulin-type fructans. Br. J. Nutr. 93:S13-S25.

Stewart, M. L., D. A. Timm, and J. L. Slavin. 2008. Fructooligosaccharides exhibit more rapid fermentation than long-chain inulin in a vitro fermentation systems. Nutr. Res. 28:329-334.

Tárrega, A., and E. Costell. 2006. Effect of inulin addition on rheological and sensory properties of fat-free starch-based dairy desserts. Int Dairy J. 16:1104-1112.

Tungland, B. C., and D. Meyer. 2002. Non-digestible oligosaccharides (dietary fibre): Their physiology and role in human health and food. Compr. Rev. Food Sci. Food Saf. 3:73-92.

Verbeke, W. 2006. Functional foods: Consumer willingness to compromise on taste for health? Food Qual. Prefer. 17:126-131.

Villegas, B., I. Carbonell, and E. Costell. 2007. Inulin milk beverages: Sensory differences in thickness and creaminess using r-index analysis of the ranking data. J. Sens. Stud. 22:377-393.

Villegas, B., and E. Costell. 2007. Flow behaviour of inulin-milk beverages. Influence of inulin average chain length and of milk fat content. Int. Dairy J. 17:776-781. 